\title{
Label-free quantum dot conjugates for human protein IL-2 based on molecularly imprinted polymers
}

\author{
Ana Margarida L. Piloto ${ }^{\mathrm{a}, \mathrm{c}}$, David S.M. Ribeiro ${ }^{\mathrm{b}}$, S. Sofia M. Rodrigues ${ }^{\mathrm{b}}$, João L.M. Santos ${ }^{\mathrm{b}}$, \\ Maria Goreti Ferreira Sales ${ }^{\mathrm{a}, \mathrm{c}, *}$ \\ ${ }^{a}$ BioMark/ISEP, School of Engineering of the Polytechnic Institute of Porto, Portugal \\ ${ }^{\mathrm{b}}$ LAQV, REQUIMTE, Univ Porto, Fac Pharm, Lab Appl Chem, Dept Chem Sci, Porto, Portugal \\ ${ }^{\mathrm{c}} \mathrm{CEB}$, Centre of Biological Engineering, Minho University, Portugal
}

\section{A R T I C L E I N F O}

\section{Keywords:}

Quantum dots

Molecularly imprinted polymer

Conjugated-Qds

Protein

interleukin-2

Cancer biomarker

\begin{abstract}
A B S T R A C T
Herein, the development of a fluorescent-based sensor by combining quantum dots (QDs) with molecularlyimprinted technology (MIT), intensively optimized to generate exceptional operating features is presented. This sensor is designed to target human interleukin-2 (IL-2) in synthetic human serum. IL-2 is a regulatory protein released as a triggered response from the immune system towards an inflammation.

For this purpose, cadmium telluride (CdTe) QDs are prepared with 3-mercaptopropionic acid (MPA) and modified afterwards to produce an IL-2 imprinted polymer with methacrylic acid and $N, N^{\prime}$-methylenebis(acrylamide), upon removal of the template under optimized conditions. During IL-2 rebinding, the fluorescence intensity of CdTe@MPA QDs is quenched in a concentration dependent manner. Using surface imprinting technology, the optimal fluorescence signals yielded a linear response versus logarithm of IL-2 concentration from $35 \mathrm{fg} / \mathrm{ml}$ to $39 \mathrm{pg} / \mathrm{ml}$, in a 1000 -fold diluted synthetic human serum. The limit of detection obtained is $5.91 \mathrm{fg} / \mathrm{ml}$, lying below the concentration levels of IL-2 with clinical interest for cancer diagnosis (9.4-19.2 pg/ $\mathrm{ml})$.

Overall, the method presented herein is a demonstration that the combination of MIP and QDs for protein detection constitutes a powerful tool in clinical analysis, providing low cost, sensitive and quick responses. The same concept may be further extended to other proteins of interest.
\end{abstract}

\section{Introduction}

The ability to detect biomarkers in body fluids at the point of care (POC) is becoming a key element in diagnosis. Increased attention on both disease prevention and/or recurrence has prompted research towards the development of expeditious biosensors for early-stage diagnosis, with both high sensitivity, selectivity and quick results.

Cytokines are molecules involved in both innate and adaptive immunity, playing a significant physiological role in lymphoid tissue ontogenesis, organogenesis and tissue repair. When the expression of these molecules is chronically altered, diseases often occur. In particular, cytokines and chemokines deregulation can support the onset of pathologies linked to chronic inflammation, tumorigenesis and autoimmunity $[1,2]$.

Interleukin-2 (IL-2) is a $15.5 \mathrm{kDa}$ cytokine produced by $\mathrm{T}$ lymphocytes that is responsible for T-cell proliferation. It was first reported as a
"T cell growth factor" as it is implicated in several stimulatory effects on natural killer (NK) cells, natural killer T (NKT) cells, and B cells, by increasing the growth and activity of T and B lymphocytes. IL-2 affects multiple signal pathways and its deficiency causes the multifaceted dysregulation of immune response. It is considered a reliable indicator of several immunodeficiency pathologies and of the immune system condition even after chemotherapy treatments [3].

The possibility to monitor IL-2 concentrations with high sensitivity in body fluids (serum and/ or urine) at early-stage diagnosis is paramount to the success therapies of several pathologies. Elevated levels of this biomarker are related to malignant cancers [4] and several other malignancies including chronic liver disease [5], acute respiratory distress syndrome [6], neurodegenerative diseases like Parkinson [7] and Alzheimer [8].

Enzyme-linked immunosorbent assays (ELISAs) are standard widespread protocols for detecting IL-2 protein in clinical diagnostic

\footnotetext{
* Corresponding author at: BioMark, Sensor Research, Instituto Superior de Engenharia do Porto, Rua Dr. António Bernardino de Almeida 431, 4249-015 Porto, Portugal.

E-mail address: mgf@isep.ipp.pt (M.G. Ferreira Sales).
} 
applications. Commercial ELISA kits can detect basal levels of IL-2 in human serum at concentrations as low as $2 \mathrm{pg} / \mathrm{ml}$. These methods are sensitive in the range of body fluid concentrations, but many lack reproducibility when applied at early phase detection, due to very low concentrations of the biomarker [9]. Several immunochemical kits are commercially available for sensitive and multiplexed detection of biomarkers. Their major limitations for POC testing are mainly related to time-consuming protocols, usually requiring trained personnel and long waiting periods for obtaining reliable results. Moreover, they often need expensive instrumentation and extra costly reagents, limiting their suitability and sustainability for POC application [10]. Hence, to facilitate accurate, rapid and reliable testing at low cost, alternative approaches are required at early diagnosis, like the work we present herein.

Some optical methods are devoted to screen IL-2 using label-free strategies. These include fluorescence staining assays [11] or surface plasmon resonance (SPR)-based sensors, where a detection limit of $100 \mathrm{pg} / \mathrm{ml}$ for IL-2 secretion from Jurkat cells, a human cancer cell line, was reported [12]. Recently, Su et al. reported the detection of IL-2 individual molecules in one-component solutions. They use optical resonators such as microtoroids to detect individual molecules with a radius of $12.5 \mathrm{~nm}$ in an aqueous solution without the use of labels [13].

Another approach that could be employed for screening IL-2 includes molecularly-imprinted polymers (MIPs) with cavities that are the molecular mould of the target analyte and to which this analyte interacts with high affinity by non-covalent interactions. These cavities can be supplemented with special moieties that act as tags to promote the analyte interaction. MIPs are formed by a combination of template molecules with adequate functional monomers and crosslinkers. Recently, MIP assemblies have shown evidences of potential application in the detection of some biomarkers, with low limits of detection and rapid diagnosis results [14-19], but none of these works are related to IL-2 detection. Moreover, the combination of MIPs with fluorescencebased sensors for protein detection in emerging with great relevance in the field of optical sensing due to their high sensitivity and specificity, along with a fast response and simplicity of implementation. In this context, quantum dots (QDs) made typically of semiconductor materials (like cadmium selenide, CdSe, and cadmium telluride), but also from carbon and silicon, have gathered a noteworthy reputation as advantageous fluorescent probes. Exhibiting high photostability, strong photoluminescence, size-tuneable broad excitation and sharp emission profiles along with ease of conjugation and functionalization [20], have outperformed the classic organic fluorescent dyes, providing the flexibility to work in a wider optical absorption/ emission window with a longer lifetime [21].

In the past years, several MIPs conjugated to QDs have been explored for specific recognition of proteins in biological fluids, due to their promising features in biosensing [22,23]. The conjugation to polymers takes place usually at the shell surface, were the recognition element (template) is moulded through a molecular imprinting process.

Thus, this work combines MIP and semiconductor nanoparticles CdTeMPA QDs, to detect IL-2 in synthetic human serum with a sensitivity down to the $\mathrm{fg} / \mathrm{ml}$. This is done by tailoring MIP materials around CdTe QDs assembled with an MPA shell. Non-imprinted polymers (NIPs) were used as controls and the most relevant variables for assembling MIP-QDs were optimized. The best MIP-QDs conjugates were applied to the analysis of diluted serum samples and the results obtained have provided a rapid (up to $30 \mathrm{~min}$.) and a low-cost alternative to the detection of IL-2, as the estimated cost of production of the pair of MIP-and NIP-conjugates is approximately $1.7 €$.

\section{Experimental section}

\subsection{Materials and chemicals}

Tellurium powder (200 mesh, $99.8 \%$ ), sodium borohydride
(NaBH4, $99 \%$ ), cadmium chloride hemi(pentahydrate) (CdCl2.2.5H2O, $99 \%$ ), methacrylic acid (MAA), $N, N^{\prime}$-methylenebis(acrylamide) (MBA) and IL-2 human, recombinant, expressed in E. coli, lyophilized powder were purchased from Sigma; 3-mercaptopropionic acid (MPA, $99 \%$ ) and absolute ethanol (99.5\%) were obtained from Fluka and Panreac respectively. 2-aminoethyl methacrylate hydrochloride (AEMH.HCl), phosphate buffered saline (PBS) from Aldrich, ammonium persulfate (APS) and tetramethylethylenediamine (TEMED) were obtained from Analar Normapur and TCI respectively. Human serum HN was purchased from PZ CORMAY S.A., Poland. All solutions were prepared with water from a Milli-Q system (specific conductivity $<0.1 \mu \mathrm{S} \mathrm{cm}{ }^{-1}$ ) and chemicals of analytical reagent grade quality. Reagents were not subject to further purification.

\subsection{Instrumentation}

Fluorescence spectra were obtained on a Lumina fluorescence spectrometer (Thermo Scientific) equipped with a $150 \mathrm{~W}$ continuous wave Xenon-arc discharge lamp as a light source. These spectra were typically taken at a scanning rate of $600 \mathrm{~nm} / \mathrm{min}$ with $20 \mathrm{~nm}$ excitation/emission slits and a $300 \mathrm{~V}$ photomultiplier tube voltage. UV-vis spectra $(200-800 \mathrm{~nm})$ were recorded on an Evolution $220 \mathrm{UV}$-vis spectrophotometer (Thermo Scientific). Fourier-transform infrared (FTIR) spectra were collected using a Nicolet iS10 spectrometer (Thermo Scientific) coupled to an attenuated total reflectance (ATR) sampling accessory of diamond contact crystal with a resolution of $32 \mathrm{~cm}^{-1}$ and a spectral range of $4000-800 \mathrm{~cm}^{-1}$. Raman analysis was performed in a DXR Raman equipment (Thermo Scientific) using a $532 \mathrm{~nm}$ excitation laser in the Raman shift from 100 to $3600 \mathrm{~cm}^{-1}$, in combination with a $50 \times$ objective magnification, a confocal aperture of $25 \mu \mathrm{m}$ pinhole, $0.9 \mathrm{~mW}$ power and total exposure of $120 \mathrm{~s}$.

The thermal behaviour of the MIPs/NIPs QDs were evaluated in the thermogravimetry (TG)/differential thermal analyzer (DTA) Exstar TG/ DTA 7200. All studies were conducted under nitrogen atmosphere $(100 \mathrm{mg} / \mathrm{ml})$ at a rate of $20^{\circ} \mathrm{C} / \mathrm{min}$, over $40-1000{ }^{\circ} \mathrm{C}$. Samples had an average of $3 \mathrm{mg}$ of dried weight.

The surface morphology of all QD nanostructures were investigated using a field emission gun scanning electron microscope (FEG-SEM; JEOL-JSM7001 F) operated at an accelerating voltage of $15 \mathrm{KV}$. Dynamic Light Scattering (DLS) and Zeta Potential analysis were performed on a Partica SZ100 series Nanoparticle Analyzer (HORIBA).

The measurement of the quantum yield (QY) of the synthesized QDs was performed using a calibrated Quantaurus-QY stand-alone integrating sphere setup C11347-11 (Hamamatsu Photonics, Hamamatsu, Japan) equipped with an integration sphere, a monochromator, a spectrograph, a $150 \mathrm{~W}$ xenon light source and a silicon charge coupled device.

Fluorescence lifetime were measured with a DeltaFlexTM TCSPC Lifetime spectrofluorometer (Horiba Scientific, Kyoto, Japan) equipped with a NanoLED pulsed light source, DeltaHub timing electronics and PPD picosecond detection modules.

\subsection{Assembly of the conjugates MIP-and NIP-CdTe@MPA QDs}

The synthesis of 3-mercaptopropionic acid-capped cadmium telluride quantum dots, CdTe@MPA QDs was performed according to Piloto et al., 2018 [22]. The resulting dried solids were ready to use and stored in a desiccator protected from light.

The conjugates MIP- and NIP-CdTe@MPA QDs were prepared by two different strategies: bulk imprinting and surface imprinting (Scheme 1). In bulk imprinting (Scheme 1A), CdTe@MPA QDs $\left(2.21 \times 10^{-6} \mathrm{M}\right)$ were incubated together with IL-2 $\left(2.15 \times 10^{-7} \mathrm{M}\right)$, AEMH.HCl $\left(3.15 \times 10^{-4} \mathrm{M}\right)$, followed by the addition of MAA $\left(5.84 \times 10^{-5} \mathrm{M}\right)$, MBA $\left(1.75 \times 10^{-4} \mathrm{M}\right)$ and freshly prepared TEMED $\left(2.23 \times 10^{-6} \mathrm{M}\right)$ and APS $\left(1.46 \times 10^{-6} \mathrm{M}\right)$ in $10 \mathrm{mM}$ PBS pH 6.5. All solutions were previously deaerated with $\mathrm{N}_{2}$ for $15 \mathrm{~min}$. Solutions of 
$\mathbf{A}$

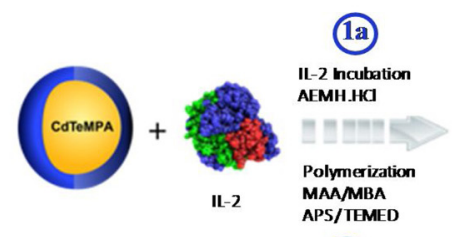

(2)
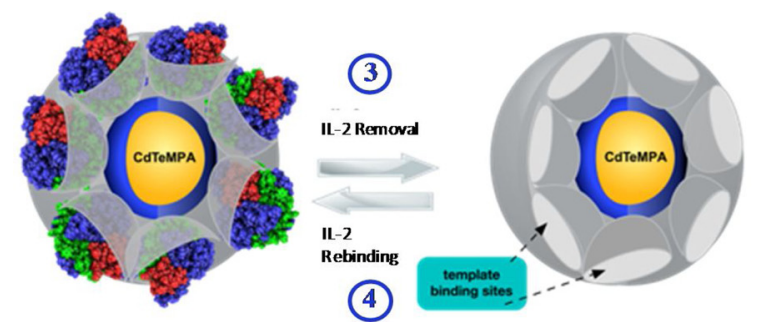

B

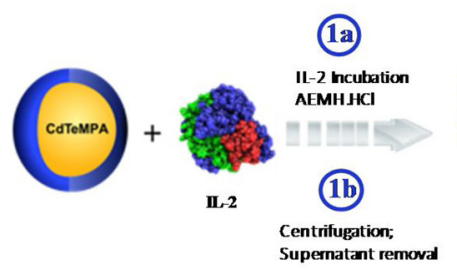

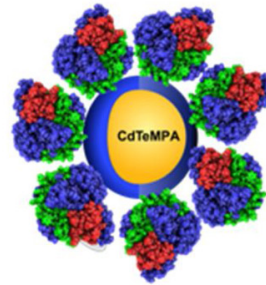

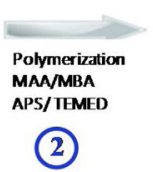

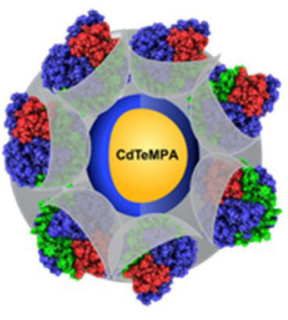

Scheme 1. (A) Bulk imprinting strategy for the preparation of the conjugated-QDs; (B) Surface imprinting strategy for the preparation of the conjugated-QDs.

NIP-QDs, were prepared in parallel, but without addition of the protein. Both solutions of MIP- and NIP-QDs were kept under magnetic stirring at room temperature, during $2 \mathrm{hs}$. After, the solutions were centrifuged at $8000 \mathrm{rpm}$ and the supernatants removed to further assess the presence of protein under UV/Vis. The pellets were washed several times with PBS $10 \mathrm{mM}$, until no protein was detected in the washing solutions.

The same conditions were applied for surface imprinting strategy with some modifications (Scheme 1B). Briefly, CdTe@MPA QDs $\left(2.21 \times 10^{-6} \mathrm{M}\right)$ were first incubated with IL-2 $\left(2.15 \times 10^{-6} \mathrm{M}\right)$ at room temperature, in PBS $10 \mathrm{mM} \mathrm{pH}$ 6.5. Next, AEMH.HCl $\left(3.15 \times 10^{-4}\right.$ M) was added and the mixture was kept stirring for $1 \mathrm{~h}$. The solutions were centrifuged, and the supernatants removed. After, MAA $\left(5.84 \times 10^{-5} \mathrm{M}\right)$ and MBA $\left(1.75 \times 10^{-4} \mathrm{M}\right)$ were added together with freshly prepared TEMED $\left(2.23 \times 10^{-6} \mathrm{M}\right)$ and APS $\left(1.46 \times 10^{-6} \mathrm{M}\right)$. All solutions were previously deaerated. The polymerization proceeded under magnetic stirring at room temperature, during $2 \mathrm{hs}$. After the centrifugation step, the same protocol was followed as for bulk imprinting.

Several experimental conditions were tested to optimize the IL-2 imprinting conditions, varying the ratios of monomer and crosslinker and the imprinting concentrations of IL-2, but maintaining the same concentration of CdTeMPA QDs in solution $\left(2.21 \times 10^{-6} \mathrm{M}\right)$ (Table S2, Fig. 5).

\subsection{Fluorescence measurements}

All fluorescence detection measurements were performed under the same condition. The excitation wavelength was set to be $360 \mathrm{~nm}$ with a recording emission range of $550-750 \mathrm{~nm}$. The fluorescence signal was monitored in PBS buffer and in synthetic human serum.

Three concentrations of IL2 were imprinted to a final volume of $1 \mathrm{ml}$ PBS $10 \mathrm{mM}, \mathrm{pH} 6.5$, using different combinations of monomer and crosslinker (Table S2). Each combination was made in replicate and the resultant conjugated MIP- and NIP- QDs subjected to calibrations with the IL-2 standards in PBS, upon template removal according to section 2.4. (Table S3).

Rebinding experiments were carried out to determine the binding affinity for target protein IL-2. A standard initial solution of IL-2 with concentration of $0.6 \mu \mathrm{M}$ was prepared in phosphate buffer $(10 \mathrm{mM}, \mathrm{pH}$ 6.5).

To perform the rebindings of IL-2, standard solutions with concentration ranging from $60 \mathrm{pM}$ to $0.6 \mu \mathrm{M}$ were prepared by diluting with phosphate buffer. Increasing volumes (microliter range) were added to the initial $1 \mathrm{ml}$ solution containing the conjugated MIP- and NIP-CdTeMPA QDs. Both conjugates were incubated in parallel for $30 \mathrm{~min}$. at room temperature and the fluorescence signal was plotted as a function of the total IL-2 concentration.

Individual fluorescence signals were collected, and the corresponding relative errors calculated. Replicates of the conjugates were prepared in parallel for all assays in PBS $10 \mathrm{mM} \mathrm{pH}$ 6.5. Selectivity studies were conducted upon resuspension of the QD conjugates in a 1000 -fold diluted synthetic human serum in PBS $10 \mathrm{mM}$ pH 6.5.

\section{Results and discussion}

\subsection{FT-IR characterization}

Fourier-transform infrared spectroscopy (FTIR) was used to characterize the conjugated-QDs. FTIR spectra of raw QDs and the conjugated-QDs are compared in Fig. 1. The carboxylic groups at the surface of CdTe@MPA QDs are in the form of carboxylate anions (attending to the working buffer used, PBS $10 \mathrm{mM} \mathrm{pH}=6.5$ ). Peaks of symmetric and asymmetric stretching vibration of $\mathrm{COO}^{-}$, from the mercapto/carboxylic acid groups of raw QDs, appear at 1400 and $1564 \mathrm{~cm}^{-1}$, respectively (Fig. 1, green), along with the stretching band of $\mathrm{OH}^{-}$, around $3400 \mathrm{~cm}^{-1}$. These peaks are softened in the conjugated-QDs (Fig. 1, red and purple), owing to the lining of the polymeric matrix around the surface of raw QDs. The band at $1725 \mathrm{~cm}^{-1}$ in MIPs and $1734 \mathrm{~cm}^{-1}$ in NIP conjugates is assigned to the $\mathrm{C}=\mathrm{O}$ vibration from the MAA and MBA monomers, confirming the existence of the polymer around the QDs-conjugates. Peaks at $1660 \mathrm{~cm}^{-1}$ in both MIPand NIP- conjugates can be attributed to the amide bonds of the polymer and at $1604 \mathrm{~cm}^{-1}$ more pronounced in the MIP spectra, correspond to the stretch of the vibration of $\mathrm{C}=\mathrm{C}$ groups residues of the vinyl unsaturation. However, these peak intensities are significantly reduced, and locations slightly deflected, which might be attributed to the formation of the polymeric matrix. The weak N-H band at $1577 \mathrm{~cm}^{-}$ ${ }^{1}$ in MIP-QDs after washings (Fig. 1, red) may be attributed to residues of protein that have not been totally removed, as it also appears in the protein spectra (Fig. 1, blue) but not in NIP-QDs. The strong $\mathrm{NH}_{2}$ band around $3200 \mathrm{~cm}^{-1}$ from the protein spectra (Fig. 1, blue) is represented by a slight protuberance at the MIP-QDs (Fig. 1, red). This confirmed the presence of residues of IL-2, possibly signalling its incomplete 


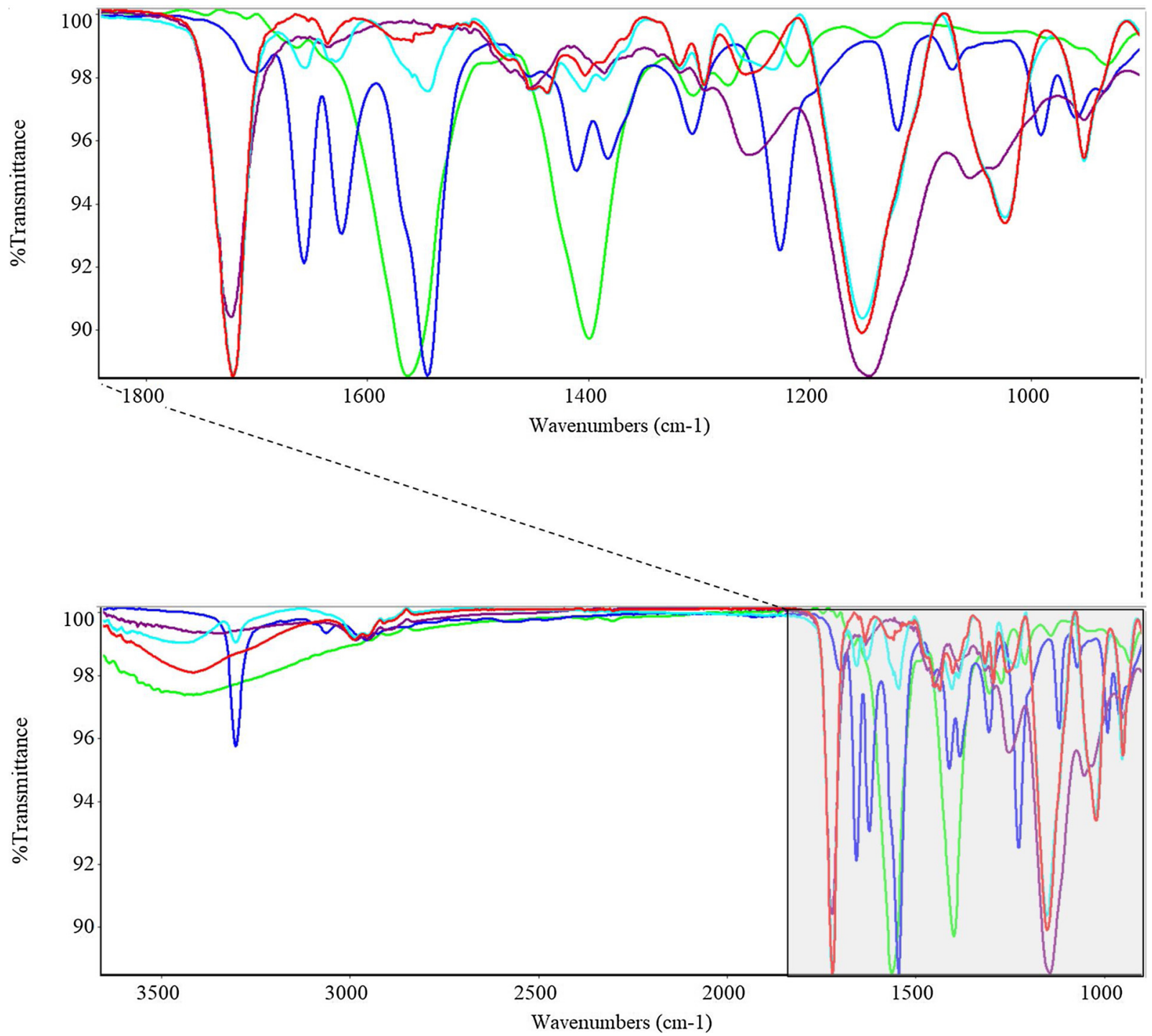

Fig. 1. FT-IR spectra of samples of raw CdTe@MPA QDs (green line), MIP-QDs polymer (light blue line); MIP-QDs after washings (red line), NIP-QDs after washings (purple line) and IL-2 protein (dark blue line).

removal from the polymeric matrix.

The bands at 990,1005, 1160, 1250 and $1350 \mathrm{~cm}^{-1}$ in both washed MIP- and NIP-conjugates (Fig. 1, red and purple) are assigned to the $\mathrm{C}-\mathrm{O}-\mathrm{C}$ vibrations of the polymeric matrix. Another significant band around $3300 \mathrm{~cm}^{-1}$ is attributed to $\mathrm{C}-\mathrm{O}-\mathrm{H}$ stretching of hydroxyl group along with the band at $2991 \mathrm{~cm}^{-1}$, attributed to the $\mathrm{CH}_{2}$ stretching of the polymer.

\subsection{Raman characterization}

Raman analysis was conducted in parallel to the FTIR studies, along the assembly of the conjugated-QDs, in a very narrow Raman shift region, from 100 to $300 \mathrm{~cm}^{-1}$. Raman spectra were collected for raw QDs (Fig. 2, red) and compared with the different stages of the assembly of the MIP-QDs (Fig. 2A) and the NIP-QDs (Fig. 2B).

According to the literature, there are three main regions linked to aqueous CdTe QDs. These regions are attributed specifically to the core of QDs, to the shell capping (which organic ligands were used during synthesis) and to the extent of interaction between the shell ligands and core of QDs. In the low Raman frequencies, between 100 and $200 \mathrm{~cm}^{-1}$ the vibrational bands are indicative of low crystallinity of the CdTe core, due to inclusions of Te sub-products on the lattice, creating surface defects. The presence of these defects lowers the crystallinity and introduces trap states, which reduces the photoluminescence quantum efficiency [24]. Specifically, peaks at $\sim 120 \mathrm{~cm}^{-1}$ correspond to the asymmetric $\mathrm{Te}_{\mathrm{A} 1}$ band; peaks at $\sim 140 \mathrm{~cm}^{-1}$ correspond to the Te E elongation band and to the transversal optical modes of CdTe TO; and peaks at $\sim 160 \mathrm{~cm}^{-1}$ are assigned to the longitudinal optical modes of CdTe LO. These modes, which are well observed in the spectra of raw QDs, are also indicative of the presence of phonon localization due to quantum confinement effects, in accordance to the presence of zerodimensional CdTe structures [25]. The modes in the mid and high Raman shifts around $300 \mathrm{~cm}^{-1}$ reveal the formation of thiolates and Cd-S bonds between the thiolates and the CdTe core, which stabilize the QDs through a structured $\mathrm{CdS}_{\mathrm{x}} \mathrm{Te}_{(1-\mathrm{x})}$ ternary compound [26].

Modifications occurring during the assembly of the conjugates, influence the vibrational mode frequencies of raw QDs, either in their Raman shift or in their intensity ratios (Fig. 2). According to Table S1, different ratios of [TeA1/ (TeE + CdTe TO)] and of (TeA1/ CdTe LO) are observed for conjugated-QDs comparting to raw QDs, as well as variations at their Raman shift. Thus, these changes confirm the existence of alterations in the fine molecular structure between the core and the shell of CdTe@MPA QDs. Raman band around $3200 \mathrm{~cm}^{-1}$ is assigned to the combined $-\mathrm{CH}_{2}$ and $-\mathrm{CH}_{3}$ asymmetric stretching 
$\mathbf{A}$

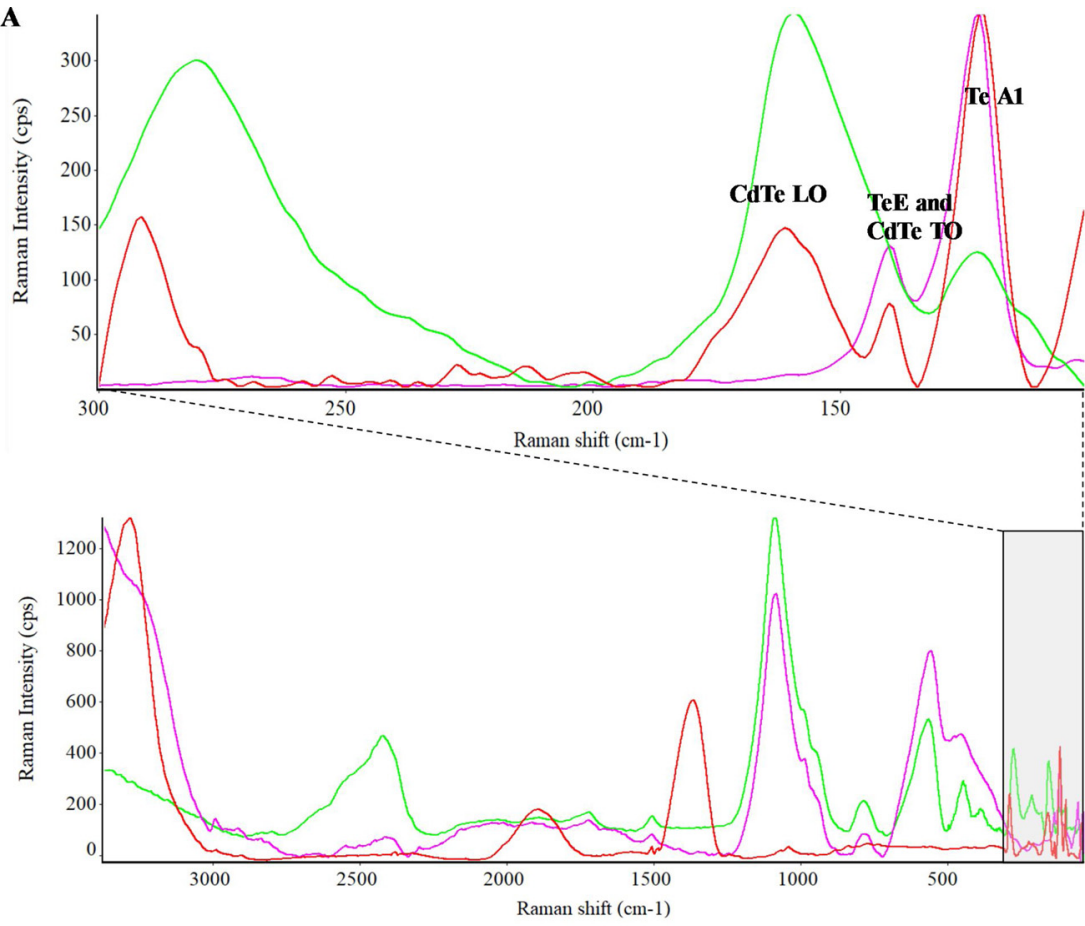

— Raw QDs; - MIP QDs polymer; — MIP-QDs washed
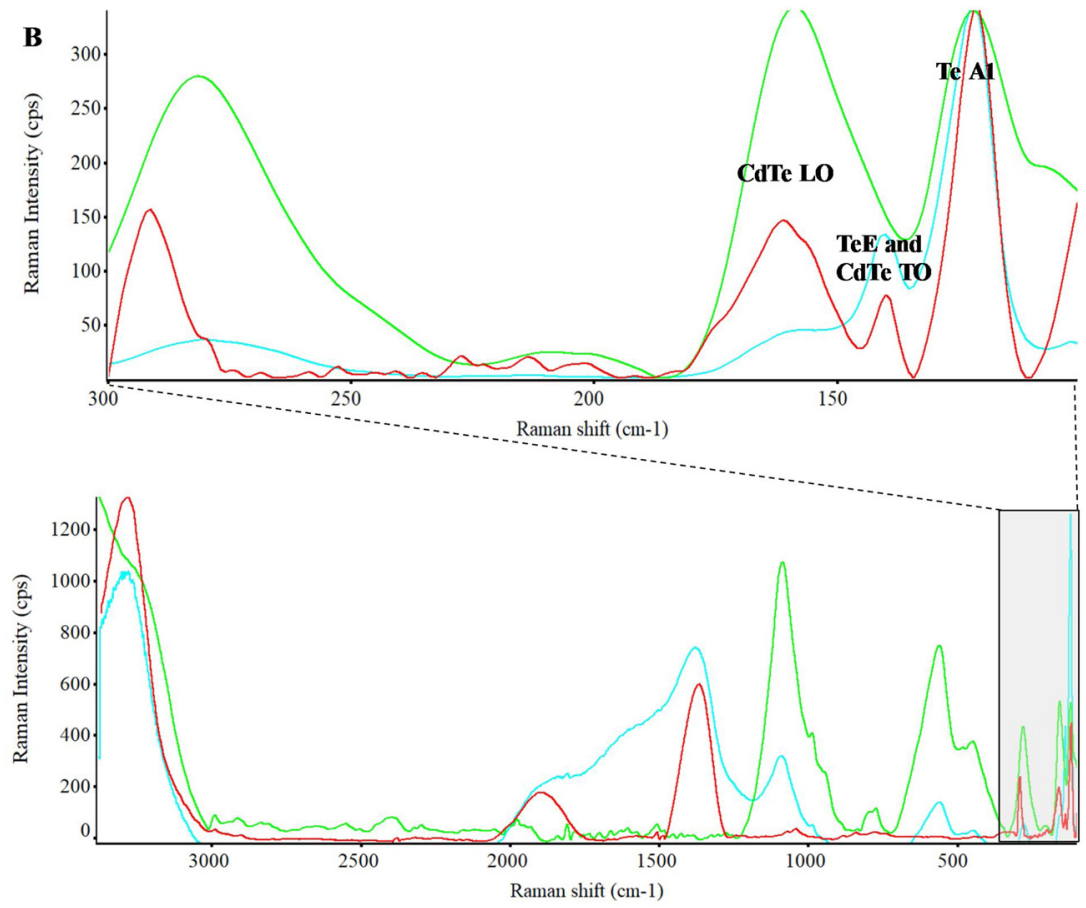

— Raw QDs; — NIP QDs polymer; - NIP-QDs washed

Fig. 2. Raman spectra of aqueous solutions of: (A) raw CdTe@MPA QDs (red line), MIP-QDs after polymerization (green line), MIP-QDs after washings (pink line); (B) raw CdTe@MPA QDs (red line), NIP-QDs after polymerization (green line), NIP-QDs after washings (light blue line).

bonds from the polymeric matrix in both conjugated-QDs (Fig. 2A and $2 \mathrm{~B}$, green). The methylene group vibrations are useful to monitor the extent of polymerization. The weak Raman band around $2400 \mathrm{~cm}^{-1}$ in the MIP-QDs polymer (Fig. 2A, green) is assigned to $=\mathrm{CH}$ stretching vibrations related to the unsaturated linkage from broth vinylic monomers [27]. The inexistence of the above frequencies in NIP-QDs polymer (Fig. 2B green line) compared to MIP-QDs polymer may also be related to the incomplete polymerization around the protein IL-2 in the imprinted materials. The bands around $1400 \mathrm{~cm}^{-1}$, only visible in the NIP-QDs polymer (Fig. 2B line light blue) arise from the $\mathrm{CH}_{2}$ bending of the polymeric matrix. The moderate bands around $1100 \mathrm{~cm}^{-1}$ present in both imprinted and non-imprinted materials correspond to $\mathrm{C}-\mathrm{C}$ polymer skeletal vibrations [27]. 


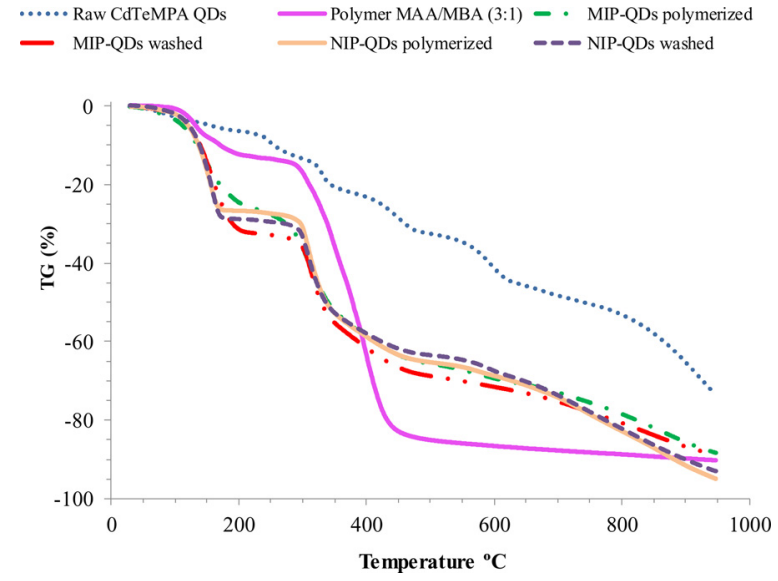

Fig. 3. Thermogravimetric plot of raw CdTe@MPA QDs (dashed black line); polymer (MAA/MBA) (3:1) (blue line); MIP-QDs after polymerization (dot and dashed green line); MIP-QDs after washings (red line); NIP-QDs after polymerization (yellow line); NIP-QDs after washings (dashed pink line).

\subsection{TGA analysis}

Thermogravimetric analysis (TGA) showed the thermal decomposition behaviour of the conjugated-QDs, thereby inferring about the polymeric shell around the modified QDs. These results obtained were compared with the raw QDs and are shown in Fig. 3.

The metallic core of QDs (CdTe) is reported to have a high melting point $\left(\sim 1000^{\circ} \mathrm{C}\right)[28]$. As the TGA assays were performed below this temperature, the significant mass loss that occurred was attributed to the degradation of the organic ligands of the shell (mercapto/carboxylic acid groups). This information indicates that the QDs synthesized are composed by $73 \%$ mass from the organic shell and $27 \%$ from the metallic core of CdTe.

The weight loss below $200{ }^{\circ} \mathrm{C}$ for both conjugated-QDs is related to their variable percentage of water content. The thermal degradation with fastest kinetics occurring between 300 and $400{ }^{\circ} \mathrm{C}$, confirmed the presence of a polymeric material on the modified QDs, as these correspond to the degradation of the polymeric matrix [29]. Despite the similar thermal behaviour of both conjugated-QDs, in the temperature range $150-200^{\circ} \mathrm{C}$, the thermal degradation of MIP-QDs follows slower kinetics than the control NIP materials. This may be attributed to the presence of the protein in MIP-QDs in this step.

In the temperature range $200-300{ }^{\circ} \mathrm{C}$ all samples containing polymer and no protein, remain stable (Fig. 3 blue, orange, red and pink). At this temperature range, the washed MIP-QDs loses extra $7.5 \%$ mass (Fig. 3 red) relative to MIP-QDs polymerized (Fig. 3 green) and the washed NIP-QDs (Fig. 3 pink) loses extra $2.5 \%$ mass relative to NIPQDs polymerized (Fig. 3 orange). The relative difference in the mass losses between the conjugated-QDs may be attributed to the extra $5 \%$ from the protein existing in MIP-QDs. At $450{ }^{\circ} \mathrm{C}$, raw QDs lose about 30 $\%$ of their initial mass, the polymer alone almost $85 \%$, corresponding to the organic polymer degradation [30] and the conjugated-QDs almost $70 \%$ of their initial mass. From $450-950{ }^{\circ} \mathrm{C}$, both conjugated-QDs lose up to $95 \%$ of their initial mass.

Overall, the thermal data collected confirmed the formation of polymer on the conjugated MIP- and NIP-QDs and signalled the different behaviour between both.

\subsection{SEM analysis}

The shape of raw CdTe@MPA QDs, conjugated MIP- and NIP-QDs were characterized by scanning electron microscopy (Fig. 4) and the particle size was calculated by statistical data. All images were acquired with the samples dissolved in ultrapure water. As shown in Fig. 4, the raw CdTe@MPA QDs are spherical in shape and present variable size diameters up to $20 \mathrm{~nm}$, arranged as cluster aggregates. Both conjugates MIP- and NIP-QDs also appeared as aggregates involved in the polymeric matrix, with a mean diameter up to $30 \mathrm{~nm}$ for the MIP-QDs and $40 \mathrm{~nm}$ for the NIP-QDs. Therefore, the difference of recognition performance between the conjugated MIP- and NIP-QDs in the following studies does not arise from morphological difference between the MIPcoated QDs and NIP-coated QDs, but to the imprinting effect.

\subsection{Fluorescence quantum yield and zeta potential analysis}

Zeta potential reveals a homogeneous distribution of raw QDs in solution, with a mean value of $-32.6 \mathrm{mV}$. This result is in accordance with the negative charge of raw QDs in PBS $10 \mathrm{mM}$, resultant from the carboxylic acid groups at their surface (pka 4.34 , at $20^{\circ} \mathrm{C}$ ).

The PL dynamic properties of the synthesized QDs were measured to determine the radiative and non-radiative relaxation rates (Table $1 \mathrm{~A}$ ). The lifetime data were fitted by a three component exponential-decay function until the residuals showed no deviation and the chi-squared value was reduced. The obtained curves displayed multi-exponential emission decays which indicate that for the synthesized QDs there are different radiative processes responsible for the fluorescence emission. For the short-lived component the fluorescence lifetime $\left(\tau_{1}\right)$ was about $2.05 \mathrm{~ns}$, while for the medium and fast-lived component, $\tau_{2}$ and $\tau_{3}$ were 12.7 and $47.6 \mathrm{~ns}$, respectively. The average lifetime ( $\left.\tau_{\text {average }}\right)$ for the whole decay process was $44.5 \mathrm{~ns}$ which was calculated as $\tau_{\text {average }}=\frac{\sum_{i} B_{i} \tau_{i}^{2}}{\sum_{i} B_{i} \tau_{i}}$, where $\mathrm{B}_{\mathrm{i}}$ represents the amplitude of each decay component and $\tau_{\mathrm{i}}$ is the respective time constant.

The quantum yield of the CdTe QDs solution (in deionized water) was determined at room temperature using an absorbance of about 0.34 in order to minimize re-absorption effects (inner filter effects). So, for an excitation wavelength of $400 \mathrm{~nm}$ the QY value of the synthesized QDs was about $34.2 \%$ which is within the range of values usually reported for these colloids (Table 1B).

\subsection{Assembly of the conjugates MIP- and NIP-CdTe@MPA QDs}

According to Piloto et al. [22], mercaptopropionic acid was used to coat the surface of the CdTe QDs. At the inner sphere of the quantum dots formation, the mercapto-group binds to the cadmium ions, through ligand competition with telluride ions. At the outer sphere the carboxylic acid groups increase the stability and water dispersibility of the nanoparticles.

During polymerization, methacrylic acid acted as the functional monomer and $N, N^{\prime}$-methylenebis(acrylamide) as the crosslinker. Additionally, the carboxylic acid groups from outer sphere of QDs and the methacrylic acid, served as assistant monomers negatively charged that helped to create effective recognition sites with amino group of the IL-2.

With the purpose of defining the best imprinting conditions, two different approaches were tested to assemble the conjugated MIP- and NIP-CdTeMPA@QDs. This includes bulk imprinting (Scheme 1A) and surface imprinting (Scheme 1B). Bulk imprinting is the classic approach but may lead to a higher amount of protein entrapped inside the polymeric network. This entrapped protein is expected to decay the blank fluorescence signal of the blank MIP-QDs, which may decrease the sensitivity of the overall calibration. In surface imprinting, the protein molecules have little possibility to remain entrapped within the polymeric network provided that the thickness of the polymeric layer is well-controlled, which is not an easy task in radical polymerization.

Three imprinting concentrations of IL-2 were tested, using $1 \mathrm{~h}$ bulk imprinting, $65 \mathrm{nM}, 129 \mathrm{nM}$ and $215 \mathrm{nM}$ (Figure S1) and different combinations of crosslinker/monomer were tested towards each concentration of IL-2 imprinted (Table S2). The calibration results were compared with raw QDs and showed in Figure S1 and Table S3. The 

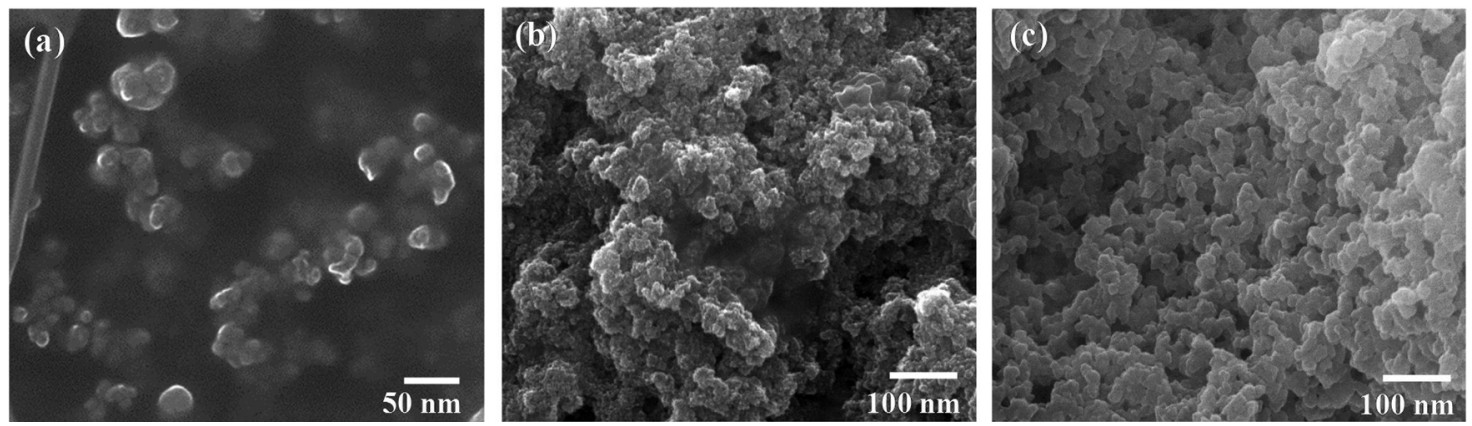

Fig. 4. SEM images of CdTeMPA QDs suspended in ultra-pure water. (a) Raw QDs, (b) MIP- QDs after washings and (c) NIP-QDs after washings.

Table 1

Parameters values obtained from the raw CdTe@MPA QDs characterization. A) PL lifetime parameters of the as-prepared raw QDs. $\tau_{\mathrm{i}}$ are the lifetimes of each decay component and $B_{i}$ their respective fractional intensity. B) Quantum yield measurements and the respective absorbance of raw QDs solution.

\begin{tabular}{llllll}
\hline & & 1st fraction & 2nd fraction & 3rd fraction & $\tau_{\text {average }}(\mathrm{ns})$ \\
\hline A & $\tau_{\mathrm{i}}(\mathrm{ns})$ & $12.7 \pm 0.3$ & $2.05 \pm 0.08$ & $47.6 \pm 0.1$ & $44.5 \pm 0.2$ \\
& $\mathrm{~B}_{\mathrm{i}}(\%)$ & 24.59 & 5.64 & 69.77 & \\
& & measure $_{1}$ & measure $_{2}$ & measure & average \\
B & QY (\%) & 34.9 & 33.7 & 34.1 & $34.2 \pm 0.6$ \\
& Abs & 0.339 & 0.342 & 0.341 & 0.341 \\
\hline
\end{tabular}

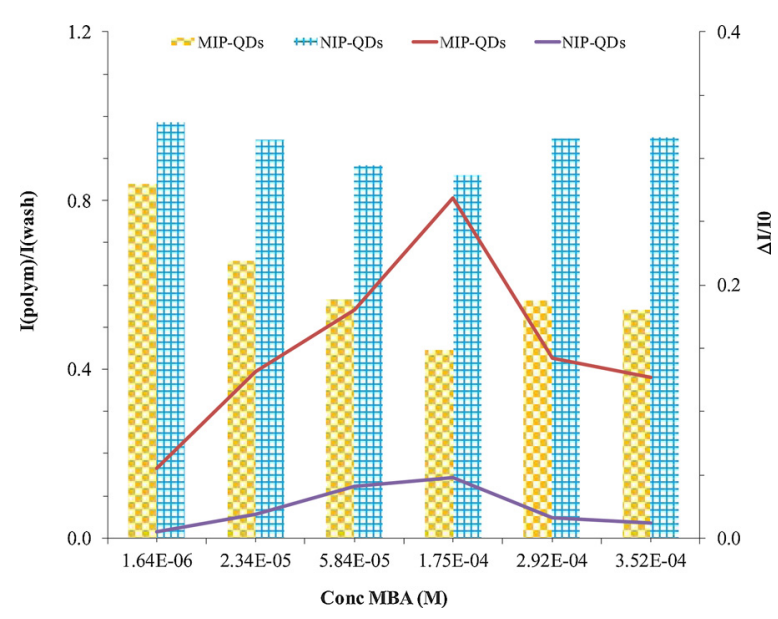

Fig. 5. Effects of the amount of monomer and crosslinker on the fluorescence intensity of conjugated MIP- and NIP-CdTe@MPA QDs, for 215 nM of IL2 imprinting in PBS $10 \mathrm{mM}$, $\mathrm{pH} 6.5$.

increase in fluorescence intensity after template removal was dependent in the proportion of (crosslinker/ monomer) used. The maximum difference in intensity ratio of (polymerization/ washings) in MIP-QDs corresponded to the best performance of MIP-QDs (Fig. 5). The best performance of the MIP-QDs was observed with $215 \mathrm{nM}$ bulk imprinting of IL-2 and with the combination of (3:1) (MBA/MAA) for the assembly of the conjugates (Fig. S1 and Fig. 5). As shown in Fig. 5, the fluorescence intensity of MIP-QDs increased until the amount of MBA reached $1.75 \times 10^{-4} \mathrm{M}$. Then with continuous addition of MBA, the fluorescence intensity gradually decreased.

For low concentrations of MBA the polymer formed around the fluorescent nanoparticles may not be sufficient to confine the QDs, contributing in some extent to their agglomeration. However, with excessive use of the MBA, the QDs become completely confined in the interior of the polymer, which will hinder the energy transfer between template protein and the QDs. Strong molecular interactions are necessary to promote a dynamic energy transfer between the cavities of the polymer and the protein molecules.
Fluorescence experiments were conducted over the $\mathrm{pH}$ range of 5.4-8.1 (Fig. 6B), using $2.5 \mathrm{pM} \mathrm{IL-2}$ standard solution. At this $\mathrm{pH}$, the zeta potential of CdTeMPA QDs is negative, whereas the IL-2 protein is positively charged [31], which may enhance electrostatic interactions with the conjugated MIP-QDs. The optimum $\mathrm{pH}$ value for the detection of IL-2 is 6.5 (Fig. 6B) in PBS $10 \mathrm{mM}$ and the optimum time necessary to reach equilibrium is $30 \mathrm{~min}$. (Fig. 6A).

Finally, the stability of the conjugate-QDs was evaluated throughout the time, upon resuspension of the obtained pellets in fresh PBS, $10 \mathrm{mM}$ $\mathrm{pH}$ 6.5. This procedure was repeated for 5 days. The results obtained are shown in Figure S6. In general, the fluorescence intensity of the conjugates did not change significantly within 5 days, thereby ensuring the reliability of the conjugated-QDs to be used as sensors for the detection of IL-2 in biological samples.

\subsection{Rebinding features of $I L-2$}

The rebinding features of the conjugated-QDs were evaluated in the presence of IL-2 standard solutions. The concentration of protein related to fluorescence quenching was monitored by the Stern-Volmer Eq. (1), through the calibration curves obtained with increasing concentrations of IL-2 standards in PBS $10 \mathrm{mM}$. In this, $\mathrm{F}$ and $\mathrm{F}_{0}$ are the fluorescence intensity of the QDs in the presence and the absence of protein respectively, $k_{\mathrm{SV}}$ is the Stern-Volmer constant and [Q] is the concentration of IL-2 standards in solution. In the experimental conditions tested, the fluorescence intensity of the MIP-QDs was gradually quenched by increasing concentrations of IL-2 standards. Herein, the plotted fluorescence signal was corrected to the final volume [Inv (I/ $\left.\mathrm{I}_{0}\right)_{\text {CORR }}$, taking into consideration the increasing volume of the solution originated with the addition of the standards (Eq. 2).

The fluorescence quenching was only effective for MIP-QDs but not for NIP-QDs (NIPs showed a random response with increasing concentration of IL-2 standards). The limit of detection (LOD) was calculated as the concentration of IL-2 that quenches three times the standard deviation of the blank signal.

$\mathrm{F}_{0} / \mathrm{F}=1+k_{\text {SV }}[\mathrm{Q}]$

$\operatorname{Inv}\left(\mathrm{I} / \mathrm{I}_{0}\right)_{\mathrm{CORR}}=\left(\mathrm{F} / \mathrm{F}_{0}\right) \times\left(\mathrm{v}_{0} / \mathrm{v}\right)$

Using $215 \mathrm{nM}$ of IL-2 with bulk imprinting, upon $1 \mathrm{~h}$ of polymerization, and three washing cycles in PBS $10 \mathrm{mM}, \mathrm{pH}$ 6.5, a linear response (LR) is observed in MIP-QDs within the range of $1.69 \times 10^{-11}$ $\mathrm{g} / \mathrm{ml}$ to $2.89 \times 10^{-8} \mathrm{~g} / \mathrm{ml}$ with a LOD of $1.37 \times 10^{-11} \mathrm{~g} / \mathrm{ml}$ (Fig. $7 \mathrm{~A}$ and Table S3). Regarding the control materials, NIP-QDs have a random behaviour, as shown in Figure S1 and Fig. 7B, thereby supporting the hypothesis that MIP-QDs conjugates are responding to the presence of IL-2. Raw QDs also decrease their fluorescence with IL-2 standards in solution, but for higher concentrations. Effectively, raw QDs, presented a linear trend from $1.17 \times 10^{-7} \mathrm{~g} / \mathrm{ml}$ to $2.07 \times 10^{-6} \mathrm{~g} / \mathrm{ml}$ and a LOD of $4.51 \times 10^{-8} \mathrm{~g} / \mathrm{ml}$ (Fig. S1 and Table S3). This behaviour was already expected and corresponds to an interference by non-selective adsorption, as their response should be affected by any other protein in 

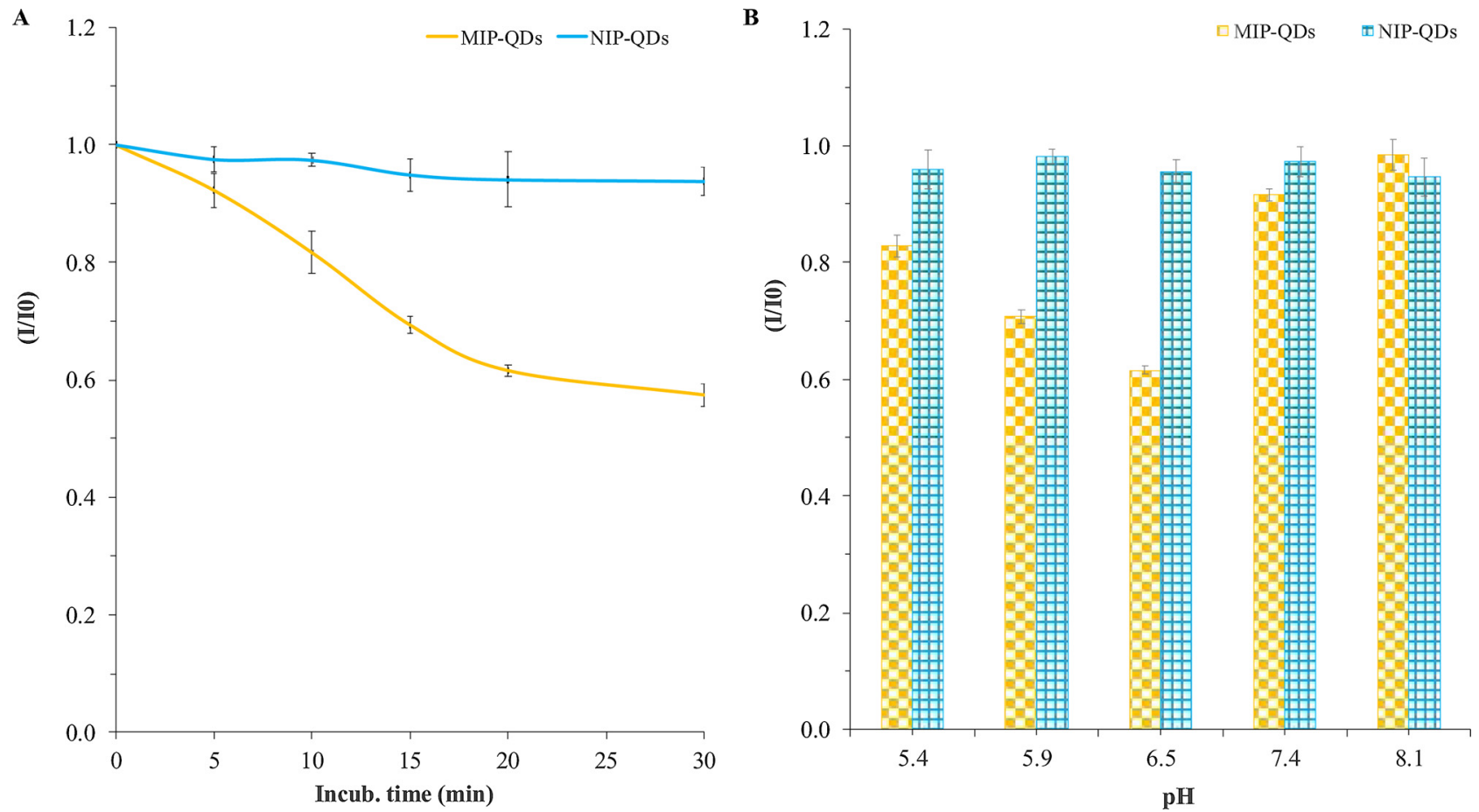

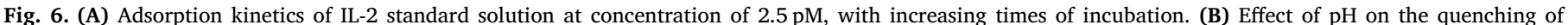
conjugated MIP- and NIP-QDs at concentration of $2.5 \mathrm{pM}$.

solution.

The time given for the polymerization to take place is critical, because it affects the thickness of the polymer formed around the QD, which in turn affects the blank signal of the conjugated-QDs and the subsequent rebinding features in the presence of the target protein. Herein, the timing for polymerization is tested first by bulk imprinting, by allowing it to take place for 1,3 and $5 \mathrm{~h}$. As shown in Figure S2, longer times of incubation decreased the analytical response of MIPQDs. In this regard, smaller Stern Volmer constants were observed with higher incubation times $\left(\boldsymbol{k}_{\mathbf{S V}}=-0.0343\right.$ with $3 \mathrm{hs} ; \boldsymbol{k}_{\mathbf{S V}}=-0.0230$ with $5 \mathrm{hs})$ comparatively with $1 \mathrm{~h}$ incubation $\left(\boldsymbol{k}_{\mathrm{SV}}=-0.0597\right)$. The best linear response was observed upon 3 hs incubation of IL-2 in bulk imprinting, with a linear range from $1.69 \times 10^{-11} \mathrm{~g} / \mathrm{ml}$ to $6.70 \times 10^{-9} \mathrm{~g}$ / $\mathrm{ml}$ and a LOD of $1.12 \times 10^{-11} \mathrm{~g} / \mathrm{ml}$ (Table S4).

These values were higher than the cut-off values reported for cancer diagnosis of Il-2 (9.4-19.2 pg/ml) [1], meaning that another strategy should be employed, such as surface imprinting. Within this strategy several conditions were tested beginning with $3 \mathrm{hs}$ incubation of IL-2 (attending the best performance from the previous studies) and different times of polymerization ( $1 \mathrm{~h}, 2 \mathrm{~h}$ and $3 \mathrm{hs}$ ), using three washings cycles in PBS $10 \mathrm{mM}, \mathrm{pH}$ 6.5. The results obtained for the imprinted conjugates are shown in Figure S3 and compared with the corresponding NIP-QDs (Table S4). Upon $3 \mathrm{hs}$ of incubation and $1 \mathrm{~h}$ polymerization, the conjugate MIP-QDs responded linearly within $7.96 \times 10^{-13} \mathrm{~g} / \mathrm{ml}$ to $4.68 \times 10^{-9} \mathrm{~g} / \mathrm{ml}$ and the LOD decreased to $1.39 \times 10^{-13} \mathrm{~g} / \mathrm{ml}$, relatively to bulk imprinting. Furthermore, increasing the time of incubation to $5 \mathrm{hs}$ and maintaining $1 \mathrm{~h}$ polymerization and the three washing cycles in PBS $10 \mathrm{mM}, \mathrm{pH}$ 6.5, the LOD of the MIP-QD sensor was slightly lower $\left(1.08 \times 10^{-13} \mathrm{~g} / \mathrm{ml}\right)$. The sensitivity also increased $\left(\boldsymbol{k}_{\mathrm{SV}}=-0.0593\right)$ and the linearity appeared for lower concentrations of IL-2 standards $\left(6.97 \times 10^{-13} \mathrm{~g} / \mathrm{ml}\right.$ to $1.81 \times 10^{-10} \mathrm{~g} / \mathrm{ml}$ ) (Table S4). Regarding the polymerization times, the results were consistent with bulk imprinting, with longer polymerizations leading to decreased sensitivities. Overall, surface imprinting strategy improved the range of linearity and for this reason it was selected for the selectivity tests (Table 2).

Another parameter that needed optimization during the surface imprinting strategy were the washings for the removal of the cytokine from the polymeric network. Considering the isoelectric point of IL-2 (7.67 [32]), it was hypothesized that performing the washing at higher $\mathrm{pH}$ would improve the cytokine removal, taking into consideration the carboxylate anions from MPA and MAA. Several washing cycles were conducted in PBS $10 \mathrm{mM} \mathrm{pH} 8.0$ and compared with the washings in PBS $10 \mathrm{mM}$ pH 6.5 (Table S4, Fig. S4). The results obtained evidenced a significant improvement in the sensitivity of MIP-QDs $\left(\boldsymbol{k}_{\mathrm{SV}}=-0.116\right)$,

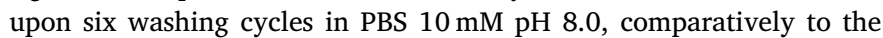
three washing cycles in PBS $10 \mathrm{mM} \mathrm{pH}$ 6.5, as shown in Fig. 7C and Fig. S4, and comparatively, the control conjugates NIP-QDs evidenced a random response (Fig. 7D).

The above results show that IL-2 can be monitored in PBS solutions $10 \mathrm{mM}$ pH 6.5, upon $215 \mathrm{nM}$ surface imprinting, $5 \mathrm{hs}$ incubation, $1 \mathrm{~h}$ polymerization and six washing cycles in PBS $10 \mathrm{mM} \mathrm{pH}$ 8.0. Replicates of these conjugates were prepared to conduct the selectivity studies.

\subsection{Selectivity tests of the conjugated-QDs in synthetic human serum}

Selectivity studies were performed by calibrating the best conjugated-QDs materials on diluted serum background, corresponding to $1000 \times$ diluted synthetic human serum in PBS $10 \mathrm{mM} \mathrm{pH} \mathrm{6.5.} \mathrm{This}$ study provides a concise information of what would happen in a real application scenario. For this purpose, standard solutions are prepared in this background and MIP-QDs are incubated as previously.

The calibration curves obtained are shown in Figure S5 and the corresponding data listed in Table 2. Compared to buffered solutions, the analytical features revealed an increase in the concentrations to which the conjugated-QDs were being sensitive, thereby affecting negatively the analytical response. Searching for further improvements and considering that the variables affecting most the performance of MIP materials are the concentration of IL- 2 to be imprinted and the template washing procedures, these two variables are re-evaluated at this point. Using $2.15 \mu \mathrm{M}$ of IL-2 with surface imprinting and three

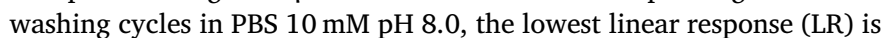
observed in MIP-QDs after three washings cycles in PBS $10 \mathrm{mM} \mathrm{pH} \mathrm{8.0,}$ within the range of $3.46 \times 10^{-14} \mathrm{~g} / \mathrm{ml}$ to $3.93 \times 10^{-11} \mathrm{~g} / \mathrm{ml}$ (or 

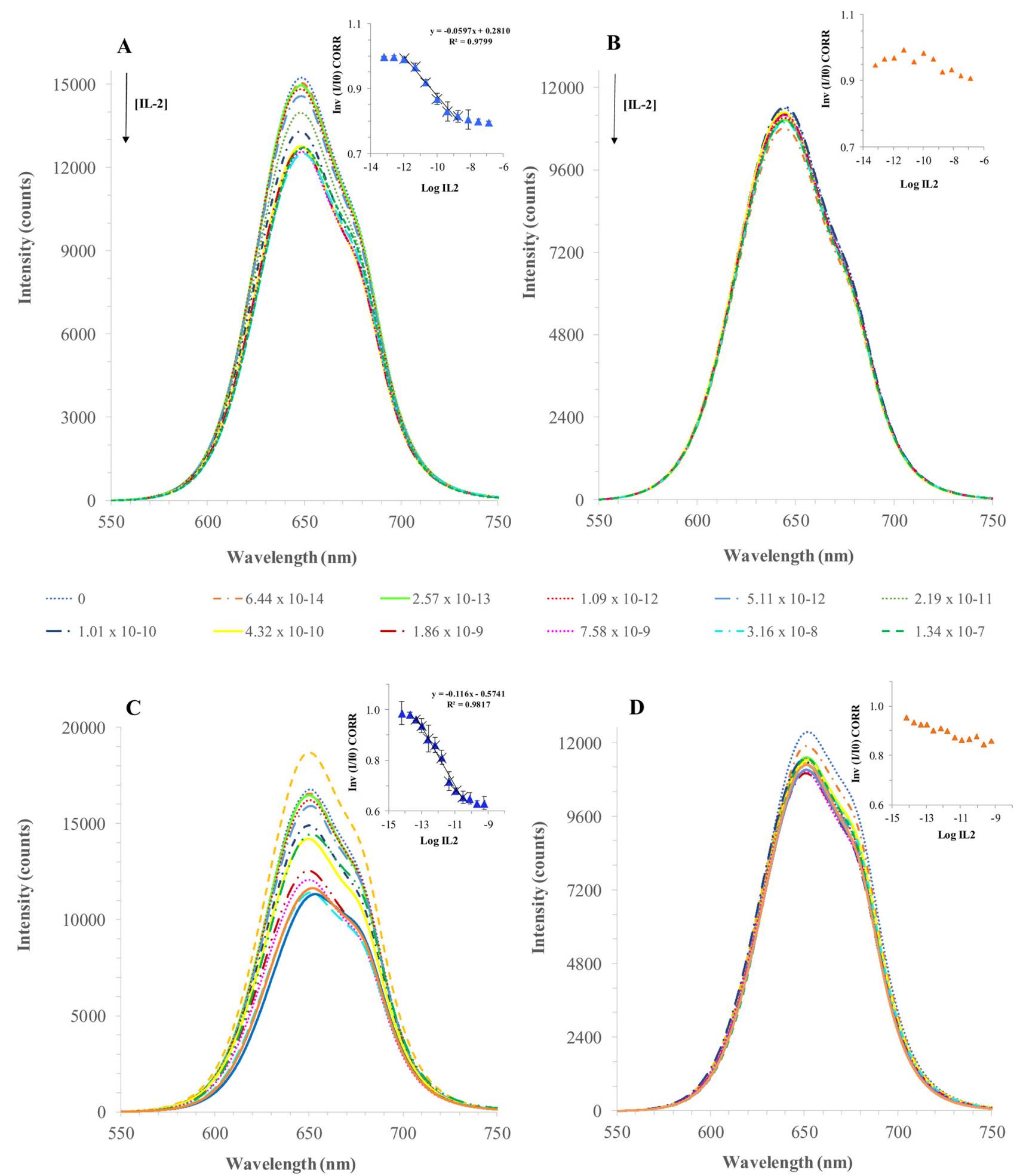

$$
\begin{aligned}
& \cdots \cdots=0-6.44 \times 10-15 \quad-1.93 \times 10-14 \quad \cdots \cdots \cdot 4.50 \times 10-14 \quad-\cdot 1.02 \times 10-13 \quad--2.52 \times 10-13 \quad-\cdot 6.53 \times 10-13
\end{aligned}
$$

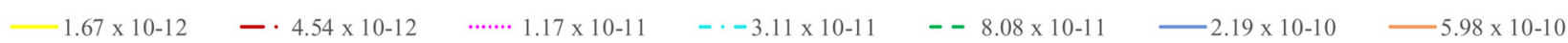

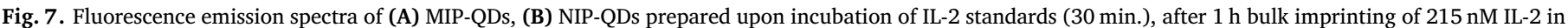

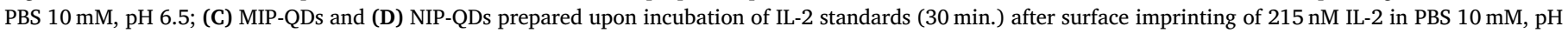
6.5 (5 h surface imprint, $1 \mathrm{~h}$ polymerization and 6 cycles washings in PBS $10 \mathrm{mM} \mathrm{pH} \mathrm{8.0).} \mathrm{Inset:} \mathrm{The} \mathrm{corresponding} \mathrm{Stern-Volmer} \mathrm{plots.}$

$2.23 \times 10^{-15}-2.53 \times 10^{-12} \mathrm{M}$ ), with a LOD of $5.91 \times 10^{-3} \mathrm{pg} / \mathrm{ml}$ (or $\left.3.81 \times 10^{-16} \mathrm{M}\right)$ (Fig. 8A and Table 2). The NIP-QDs continued showing a random response (Fig. $8 \mathrm{~B}$ ).

We had to discharge the fluorescence measure in synthetic human serum without dilution, because attending the presence of other constituents in the matrix, the fluorescence signals of both raw QDs and the conjugates MIP- and NIP-CdTeMPA@QDs were quenched up to $42 \%$ in relation to their signals in PBS $10 \mathrm{mM}$ pH 6.5. In the future it will be 
Table 2

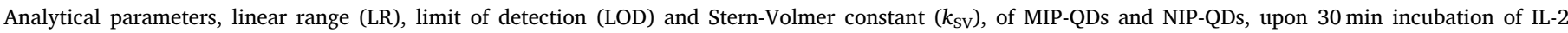

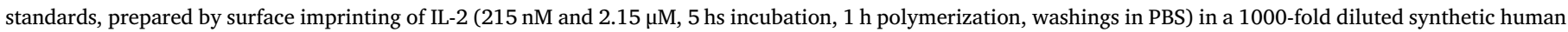
serum in PBS $10 \mathrm{mM}$ pH 6.5.

\begin{tabular}{|c|c|c|c|c|c|c|}
\hline \multirow[t]{2}{*}{ Analytical parameter } & \multicolumn{3}{|l|}{215 nM IL-2 } & \multicolumn{3}{|l|}{$2.15 \mu \mathrm{M} \mathrm{IL}-2$} \\
\hline & MIP-QD ${ }^{\text {a) }}$ & MIP-QD ${ }^{b)}$ & MIP-QD ${ }^{\text {a) }}$ & MIP-QD ${ }^{\text {a) }}$ & MIP-QD b) & MIP-QD c) \\
\hline LR (M) & $\begin{array}{l}2.17 \times 10^{-13}- \\
7.82 \times 10^{-11}\end{array}$ & $\begin{array}{l}2.17 \times 10^{-13}- \\
2.52 \times 10^{-10}\end{array}$ & $\begin{array}{l}2.17 \times 10^{-13}- \\
2.52 \times 10^{-10}\end{array}$ & $\begin{array}{l}2.23 \times 10^{-15}- \\
2.53 \times 10^{-12}\end{array}$ & $\begin{array}{l}7.04 \times 10^{-16}- \\
2.53 \times 10^{-12}\end{array}$ & $\begin{array}{l}2.23 \times 10^{-15}- \\
2.53 \times 10^{-12}\end{array}$ \\
\hline LR $(\mathrm{g} / \mathrm{ml})$ & $\begin{array}{l}3.37 \times 10^{-12}- \\
1.21 \times 10^{-9}\end{array}$ & $\begin{array}{l}3.37 \times 10^{-12}- \\
3.91 \times 10^{-9}\end{array}$ & $\begin{array}{l}3.37 \times 10^{-12}- \\
3.91 \times 10^{-9}\end{array}$ & $\begin{array}{l}3.46 \times 10^{-14}- \\
3.93 \times 10^{-11}\end{array}$ & $\begin{array}{l}1.09 \times 10^{-14}- \\
3.93 \times 10^{-11}\end{array}$ & $\begin{array}{l}3.46 \times 10^{-14}- \\
3.93 \times 10^{-11}\end{array}$ \\
\hline LOD (M) & $2.65 \times 10^{-13}$ & $6.82 \times 10^{-14}$ & $2.58 \times 10^{-13}$ & $3.81 \times 10^{-16}$ & $8.08 \times 10^{-16}$ & $7.76 \times 10^{-16}$ \\
\hline LOD $(\mathrm{g} / \mathrm{ml})$ & $4.11 \times 10^{-12}$ & $1.06 \times 10^{-12}$ & $4.00 \times 10^{-12}$ & $5.91 \times 10^{-15}$ & $1.25 \times 10^{-14}$ & $1.20 \times 10^{-14}$ \\
\hline LOD $(\mathrm{pg} / \mathrm{ml})$ & 4.11 & 1.06 & 4.00 & $5.91 \times 10^{-3}$ & $1.25 \times 10^{-2}$ & $1.20 \times 10^{-2}$ \\
\hline $\begin{array}{l}\text { Stern-Volmer } \\
\quad \text { constant }\left(k_{\mathrm{SV}}\right)\end{array}$ & -0.0892 & -0.0776 & -0.0826 & -0.1172 & -0.1065 & -0.1064 \\
\hline
\end{tabular}

a), b) and c) correspond to 3, 6 and 9 cycles of washing in PBS $10 \mathrm{mM} \mathrm{pH} \mathrm{8.0,} \mathrm{respectively.}$

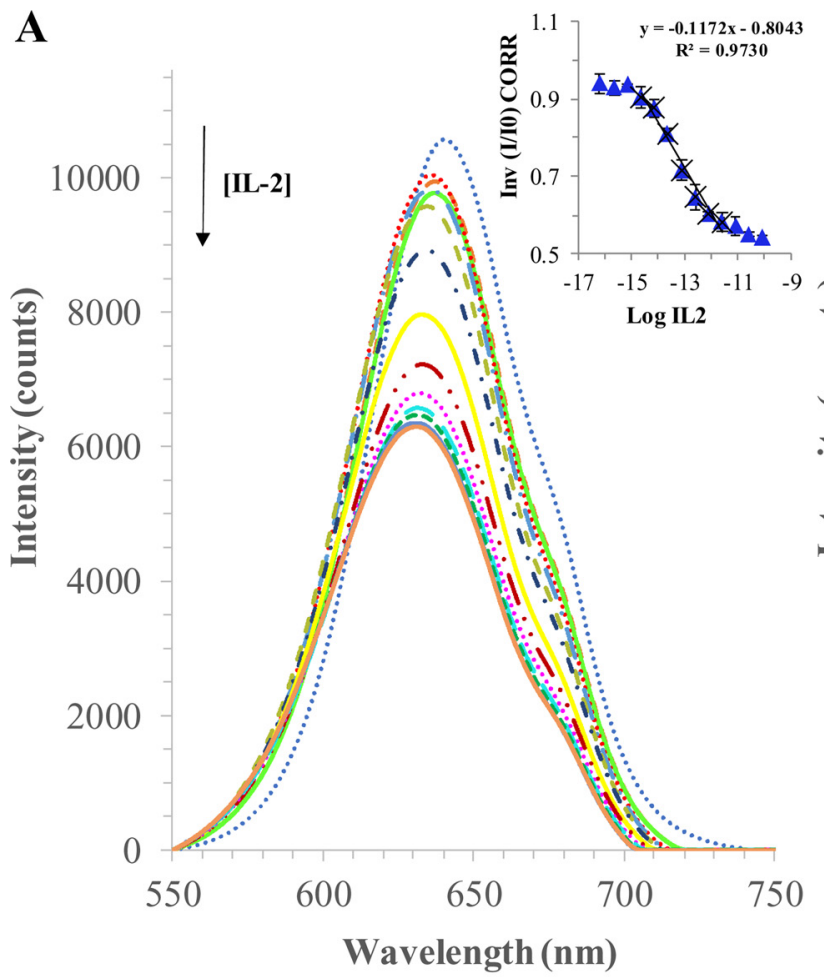

$$
\begin{aligned}
& \cdots \cdots 0 \\
& --7.20 \times 10-15 \\
& -\cdots-2.53 \times 10-12
\end{aligned}
$$
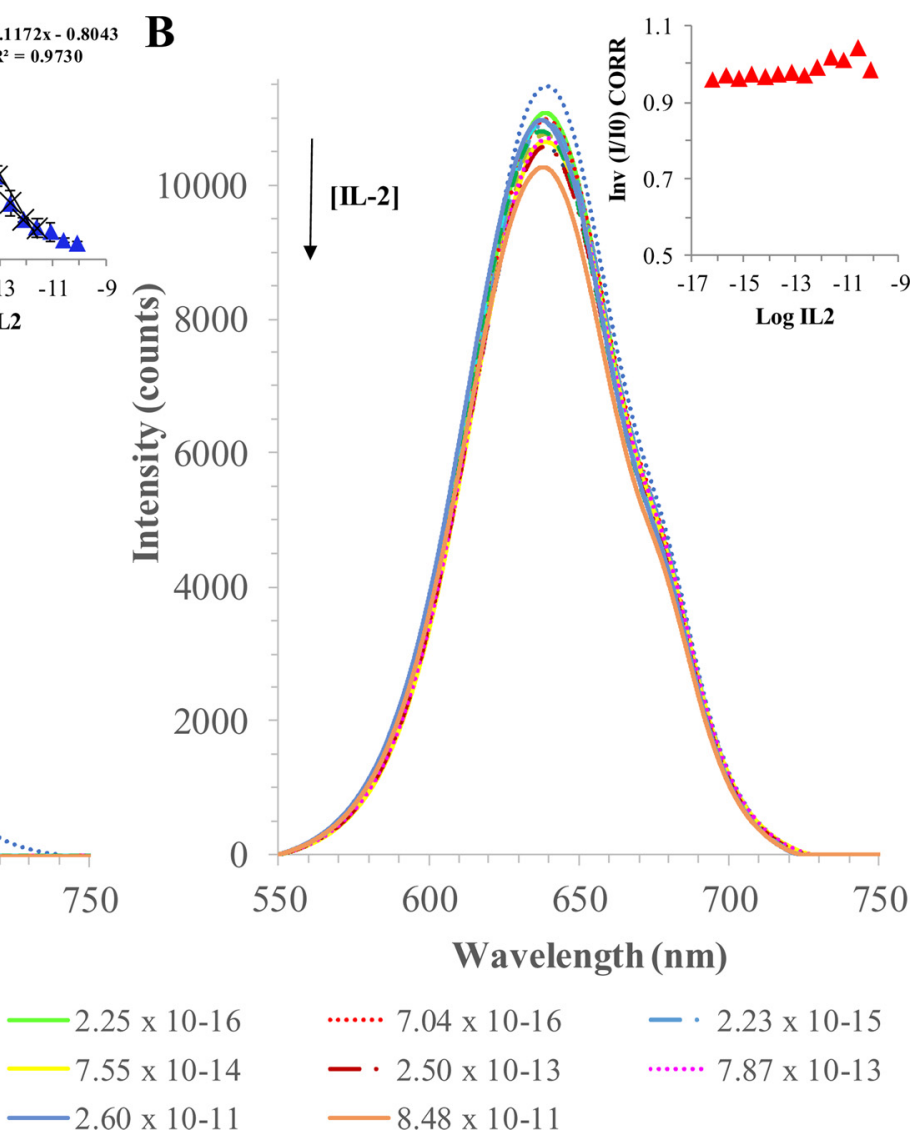

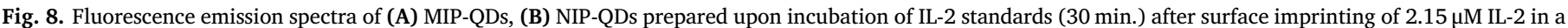

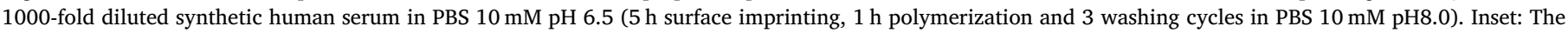
corresponding Stern-Volmer plots.

Table 3

\begin{tabular}{|c|c|c|c|c|c|}
\hline Method & Analyte detection & Linear range $(\mathrm{M})$ & Linear range $(\mathrm{g} / \mathrm{ml})$ & LOD (M) & References \\
\hline Fluorescence quenching & Lysozyme & $1.0 \times 10^{-7}-1.0 \times 10^{-6}$ & $1.4 \times 10^{-6}-1.4 \times 10^{-5}$ & $1.02 \times 10^{-8}$ & [35] \\
\hline Fluorescence quenching & Cyphenothrin & $1.0 \times 10^{-7}-8.0 \times 10^{-5}$ & $3.8 \times 10^{-8}-3.0 \times 10^{-5}$ & $9.0 \times 10^{-9}$ & [36] \\
\hline Photoluminescence quenching & Perfluorooctanoic acid & $2.5 \times 10^{-7}-1.5 \times 10^{-5}$ & $1.0 \times 10^{-7}-6.2 \times 10^{-6}$ & $2.5 \times 10^{-8}$ & [23] \\
\hline Fluorescence quenching & Sulfasalazine & $2.0 \times 10^{-8}-1.5 \times 10^{-6}$ & $7.9 \times 10^{-9}-5.9 \times 10^{-7}$ & $7.1 \times 10^{-9}$ & [37] \\
\hline Fluorescence quenching & Hemoglobin & $7.7 \times 10^{-10}-7.7 \times 10^{-9}$ & $5.3 \times 10^{-8}-5.3 \times 10^{-7}$ & $7.7 \times 10^{-10}$ & [38] \\
\hline Fluorescence quenching & IL-2 & $2.23 \times 10^{-15}-2.53 \times 10^{-12}$ & $3.5 \times 10^{-14}-3.9 \times 10^{-11}$ & $3.81 \times 10^{-16}$ & This work \\
\hline
\end{tabular}

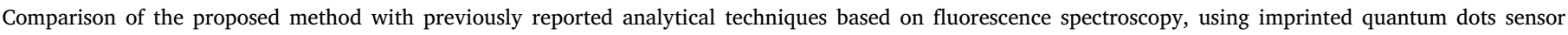
conjugates as recognition elements. 
useful to perform an ELISA test to compare with the results of linear range and LOD obtained.

In Table 3 is reported the best result obtained with the MIPCdTeMPA@QDs conjugate from Table 2, in comparison to other analytical techniques that made use of fluorescence spectroscopy in combination with molecular imprinting for the detection of IL-2. The proposed method has lower limit of detection, wider concentration range, no sample pre-treatment protocols, and rapid time of response (30 min.) (Fig. 6A). In addition, upon optimization of the surface imprinting parameters, specifically the imprinting concentration to $2.15 \mu \mathrm{M}$, the affinity constant of the MIP-conjugates enhanced up to 1.5 -fold $\left(\boldsymbol{k}_{\mathrm{sV}}=\right.$ -0.1172) comparating to the values obtained with the lower imprinting concentration of $215 \mathrm{nM}$ (Table 2).

Moreover, it is superior to the affinity constant values reported for the detection of IL-2 in aqueous medium [33,34], the major disadvantage being the fact that the samples need to be diluted before the measurements to avoid interference of the serum constituents with the optical fluorescence signal of QDs. The research results suggested that this new fluorescent molecularly imprinted conjugated-QDs can be used as biosensor for the determination of IL-2 in biological samples.

\section{Conclusions}

This work describes a successful combination of low-cost biorecognition elements as imprinted polymers with semi-conductor nanoparticles like quantum dots for sensing purposes. After careful optimization of the overall assembly process, the conjugated-QDs showed attractive characteristics, such as straightforward preparation, good dispersion and reproducibility and long-term stability in aqueous medium. Moreover, MIP-QDs materials prepared in the optimized conditions and analyzed in diluted serum background showed good selectivity and sensitivity for IL-2. Good reproducibility was also observed for replicates of MIP-QDs.

Overall, this work demonstrates that the combination of low cost and chemically stable molecular imprinted materials with analytical sensitive fluorescent nanoparticles like quantum dots, constitute an enormous potential in the context of clinical analysis. This principle may be further extended to other proteins of relevance to be applied in the screening of cancer and other diseases.

\section{CRediT authorship contribution statement}

Ana Margarida L. Piloto: Investigation, Data curation, Methodology, Validation, Writing - original draft. David S.M. Ribeiro: Formal analysis, Visualization, Methodology. S. Sofia M. Rodrigues: Formal analysis, Visualization, Methodology. Joảo L.M. Santos: Conceptualization, Supervision, Writing - review \& editing, Formal analysis, Resources, Validation. Maria Goreti Ferreira Sales: Conceptualization, Funding acquisition, Supervision, Project administration, Writing - review \& editing, Formal analysis, Resources, Validation.

\section{Declaration of Competing Interest}

The authors declare that they have no known competing financial interests or personal relationships that could have appeared to influence the work reported in this paper.

\section{Acknowledgements}

The authors acknowledge the financial support of European Research Council though the Starting Grant, 3P's Starting Grant/ERC (GA 311086) and the financial support of Portugal 2020, FEDER and NORTE 2020 through the project Strip2Sense (NORTE-01-0145-FEDER024358). AMLP also aknowledges Fundação para a Ciência e Tecnologia, I.P., for the grant reference SFRH/BPD/116067/2016.

\section{References}

[1] G. Kleiner, A. Marcuzzi, V. Zanin, L. Monasta, G. Zauli, Cytokine levels in the serum of healthy subjects, Mediators Inflamm. 2013 (2013) 434010.

[2] M.D. Turner, B. Nedjai, T. Hurst, D.J. Pennington, Cytokines and chemokines: At the crossroads of cell signalling and inflammatory disease, Biochim. Biophys. Acta 1843 (11) (2014) 2563-2582.

[3] X. Geng, R. Zhang, G. Yang, W. Jiang, C. Xu, Interleukin-2 and autoimmune disease occurrence and therapy, Eur Rev Med Pharmaco 16 (11) (2012) 1462-1467.

[4] G.C. Sim, L. Radvanyi, The IL-2 cytokine family in cancer immunotherapy, Cytokine Growth Factor Rev. 25 (4) (2014) 377-390.

[5] S.O.A.-A. Mohamed Ali El-Desouky, Afaf Abd El-Aleem, Hala Moustafa Ahmed, Hazem Mohamed El- Hariri, Hend Gaber Badawy, Biochemical studies of interleukin-2, 4, 6 and 8 in patients with chronic liver and kidney diseases, IOSR Journal of Applied Chemistry (IOSR-JAC) 7 (10) (2014) 14-19.

[6] W.Ca.L.B. Ware, Prognostic factors in the acute respiratory distress syndrome, Clin. Transl. Med. 4 (23) (2015).

[7] N.P. Rocha, A.S. de Miranda, A.L. Teixeira, Insights into neuroinflammation in parkinson's disease: from biomarkers to anti-inflammatory based therapies, Biomed Res. Int. 2015 (2015) 628192.

[8] D. Meola, Z. Huang, J.M. Petitto, Selective neuronal and brain regional expession of IL-2 in IL2P 8-GFP transgenic mice: relation to sensorimotor gating, J. Alzheimers Dis. Parkinsonism 3 (4) (2013) 1000127.

[9] M. Sobjanek, E. Bien, M. Zablotna, M. Sokolowska-Wojdylo, M. Sikorska, M. Lange, R. Nowicki, Soluble interleukin-2 receptor alpha and interleukin-2 serum levels in patients with basal cell carcinoma, Postepy Dermatol. Alergol. 33 (4) (2016) 263-268.

[10] J.F. Rusling, C.V. Kumar, J.S. Gutkind, V. Patel, Measurement of biomarker proteins for point-of-care early detection and monitoring of cancer, Analyst 135 (10) (2010) 2496-2511.

[11] C. He, P.K. Narayanan, M.M. Fort, Assessment of the performance of three multiplex array panels for the detection of circulating cytokines and chemokines in naive, LPS, and SEB-treated cynomolgus macaques, Toxicol. Pathol. 42 (1) (2014) 286-292.

[12] M.S. Luchansky, R.C. Bailey, Silicon photonic microring resonators for quantitative cytokine detection and T-cell secretion analysis, Anal. Chem. 82 (5) (2010) 1975-1981.

[13] J. Su, A.F.G. Goldberg, B.M. Stoltz, Label-free detection of single nanoparticles and biological molecules using microtoroid optical resonators, Light Sci. Appl. 5 (1) (2016) e16001.

[14] L.A.A.N.A. Truta, M.G.F. Sales, Carcinoembryonic antigen imprinting by electropolymerization on a common conductive glass support and its determination in serum samples, Sensor Actuat B-Chem 287 (2019) 53-63.

[15] A.P.M. Tavares, M.G.F. Sales, Novel electro-polymerized protein-imprinted materials using Eriochrome black T: application to BSA sensing, Electrochim. Acta 262 (2018) 214-225.

[16] F.T.C. Moreira, B.A.G. Rodriguez, R.A.F. Dutra, M.G.F. Sales, Redox probe-free readings of a beta-amyloid- 42 plastic antibody sensory material assembled on copper@carbon nanotubes, Sensor Actuat B-Chem 264 (2018) 1-9.

[17] A.R. Cardoso, A.P.M. Tavares, M.G.F. Sales, In-situ generated molecularly imprinted material for chloramphenicol electrochemical sensing in waters down to the nanomolar level, Sensor Actuat B-Chem 256 (2018) 420-428.

[18] J.R.L. Guerreiro, N. Teixeira, V. De Freitas, M.G.F. Sales, D.S. Sutherland, A saliva molecular imprinted localized surface plasmon resonance biosensor for wine astringency estimation, Food Chem. 233 (2017) 457-466.

[19] G.V. Martins, A.C. Marques, E. Fortunato, M.G.F. Sales, 8-hydroxy-2'-deoxyguanosine (8-OHdG) biomarker detection down to picoMolar level on a plastic antibody film, Biosens. Bioelectron. 86 (2016) 225-234.

[20] M.J.M. Jimenez, R.F. Oliveira, T.P. Almeida, R.C.H. Ferreira, C.C.B. Bufon, V. Rodrigues, M.A. Pereira-da-Silva, A.L. Gobbi, M.H.O. Piazzetta, A. Riul, Charge carrier transport in defective reduced graphene oxide as quantum dots and nanoplatelets in multilayer films, Nanotechnology 28 (49) (2017).

[21] L. Jing, S.V. Kershaw, Y. Li, X. Huang, Y. Li, A.L. Rogach, M. Gao, Aqueous based semiconductor nanocrystals, Chem. Rev. (2016).

[22] A.M. Piloto, D.S.M. Ribeiro, S.S.M. Rodrigues, C. Santos, J.L.M. Santos, M.G.F. Sales, Plastic antibodies tailored on quantum dots for an optical detection of myoglobin down to the femtomolar range, Sci Rep-Uk 8 (2018).

[23] L. Zheng, Y.H. Zheng, Y. Liu, S. Long, L.L. Du, J.M. Liang, C.Z. Huang, M.T. Swihart, K.J. Tan, Core-shell quantum dots coated with molecularly imprinted polymer for selective photoluminescence sensing of perfluorooctanoic acid, Talanta 194 (2019) 1-6.

[24] B. Gilbert, F. Huang, Z. Lin, C. Goodell, H.Z. Zhang, J.F. Banfield, Surface chemistry controls crystallinity of ZnS nanoparticles, Nano Lett. 6 (4) (2006) 605-610.

[25] I.L. Volodymyr Dzhagan, Cameliu Himcinschi, Xiaoping Jin, Joanna Kolny-Olesiak, Dietrich R.T. Zahn, Phonon Raman spectra of colloidal CdTe nanocrystals: effect of size, non-stoichiometry and ligand exchange, Nanoscale Res. Lett. 6 (79) (2011) 10

[26] A.A.F. Jacky, S.W. Mak, Feifan Chen, Amr S. Helmy, Photonic crystal Fiber for efficient raman scattering of CdTe quantum dots in aqueous solution, ACS Nano 5 (5) (2011) 3823-3830.

[27] M.K. Gupta, R. Bansil, Laser raman-spectroscopy of polyacrylamide, J. Polym. Sci.: Polym. Phys. Ed. 19 (2) (1981) 353-360.

[28] A. Ayyaswamy, S. Ganapathy, A. Alsalme, A. Alghamdi, J. Ramasamy, Structural, optical and photovoltaic properties of co-doped CdTe QDs for quantum dots sensitized solar cells, Superlattices Microstruct. 88 (2015) 634-644.

[29] S.C. Moldoveanu, Analytical Pyrolysis of Synthetic Organic Polymers, first edition, 
Elsevier, 2005.

[30] S.A. Pooley, B.L. Rivas, F.E. Lillo, G.D. Pizarro, Hydrogels from acrylic acid with N,N-Dimethylacrylamide: synthesis, characterization, and water absorption properties, J Chil Chem Soc 55 (1) (2010) 19-24.

[31] T. Yamada, K. Kato, K. Kawahara, O. Nishimura, Separation of recombinant human Interleukin-2 and methionyl Interleukin-2 produced in Escherichia-Coli, Biochem Bioph Res Co 135 (3) (1986) 837-843.

[32] S.M. Liang, B. Allet, K. Rose, M. Hirschi, C.M. Liang, D.R. Thatcher, Characterization of human Interleukin-2 derived from escherichia-coli, Biochem. J. 229 (2) (1985) 429-439.

[33] J. Jeon, H. Jo, J. Her, H. Youn, J. Park, J. Jo, J. Lee, C.L. Chang, C. Ban, A rapid colorimetric sensor for soluble Interleukin-2 receptor alpha, based on aptamer-adsorbed AuNP, Chembiochem (2019).

[34] E. Alipour, H. Shahabi, T. Mahmoudi-Badiki, Introducing curcumin as an electrochemical DNA hybridization indicator and its application for detection of human interleukin-2 gene, J. Solid State Electrochem. 20 (6) (2016) 1645-1653.

[35] X. Zhang, S. Yang, R. Jiang, L.Q. Sun, S.P. Pang, A.Q. Luo, Fluorescent molecularly imprinted membranes as biosensor for the detection of target protein, Sensor Actuat B-Chem 254 (2018) 1078-1086.

[36] X.H. Ren, L.G. Chen, Quantum dots coated with molecularly imprinted polymer as fluorescence probe for detection of cyphenothrin, Biosens. Bioelectron. 64 (2015) $182-188$.

[37] H. Ahmadpour, S.M.M. Hosseini, A solid-phase luminescence sensor based on molecularly imprinted polymer-CdSeS/ZnS quantum dots for selective extraction and detection of sulfasalazine in biological samples, Talanta 194 (2019) 534-541.

[38] T.C. Zhou, J. Ashley, X.T. Feng, Y. Sun, Detection of hemoglobin using hybrid molecularly imprinted polymers/carbon quantum dots-based nanobiosensor prepared from surfactant-free Pickering emulsion, Talanta 190 (2018) 443-449.

Ana Margarida Piloto received a Bachelor of Science degree in Chemistry in 2001 from Coimbra University and a Master of Science degree from Minho University in 2006, working on the synthesis and evaluation of photocleavable protecting groups for amino acids and peptides. She was awarded her doctorate in 2013 at the same University, continuing her work in the development of new fluorescent molecules for biological compounds with potential applications in phototherapy. In 2014 she joined BioMark sensor research group, in ISEP, the School of Engineering of the Polytechnic School of
Porto, as a postdoc researcher, where she presently devotes her work to the development of new fluorescent cellulose sensors for protein cancer biomarkers.

David Ribeiro obtained his $\mathrm{PhD}$ degree in Pharmaceutical Sciences, speciality in Analytical Chemistry (2012) and MSc degree in Analytical Chemistry - Quality Control (2007) from Faculty of Pharmacy, University of Porto. He is a Researcher at REQUIMTE (LAVQ) Associate Laboratory, Faculty of Pharmacy, University of Porto. His actual interest is the synthesis and characterization of quantum dots for analytical purposes. He is carrying out research on the development of new analytical methodologies combining the sensitivity offered by nanomaterials, as quantum dots, and the versatility, low cost and portability of flow-based analytical techniques for chemical analysis.

Sofia Rodrigues received her $\mathrm{PhD}$ degree in Pharmaceutical Sciences, speciality in Nanotechnologies (2015) and MSc degree in Analytical Chemistry - Quality Control (2009) from Faculty of Pharmacy, University of Porto. She is currently a postdoctoral fellow at the associate laboratory REQUIMTE, Oporto University. Her research interest is focused on the development of chemo-sensing schemes based on analyte-triggered modulation of CdTe quantum dots photoluminescence for analytical purposes.

Joao Santos received his $\mathrm{PhD}$ in Analytical Chemistry in 2000 from Faculty of Pharmacy, University of Porto. He is Auxiliary Professor at the Faculty of Pharmacy, University of Porto, and research scientist at REQUIMTE Associate Laboratory. His research activities have been focused in the development of automated flow-based methodologies, mainly multicommutation, multipumping and single reaction interface flow systems. His current interests include nanotechnology and nanomaterials, namely quantum dots and metallic nanoparticles for photoluminescent detection and nanodiagnostics.

Goreti Sales received a degree in pharmaceutical sciences in 1994 and a $\mathrm{PhD}$ in analytical chemistry in 2000, all from the Faculty of Pharmacy of Porto University. She is adjunct professor in the Polytechnique Institute, School of Engineering, since 2006. Her research interests are mainly devoted to research on biomimetic nanomaterials and biosensing devices. She is the founder of the research group BioMark, Sensor Research (in 2011) and she was awarded (in 2012) a Starting Grant by the European Research Council, targeting a new technical approach that merges biosensors with solar cells. She is currently coordinating the FET-Open project (H2020) MindGAP. 